\title{
Impact of HIV Positive Status on Reproductive Decision M aking
}

\author{
${ }^{1}$ Ranjana Tibrewal, ${ }^{2}$ Sebanti Goswami \\ ${ }^{1}$ Postgraduate Trainee, Department of Obstetrics and Gynecology, Medical College and Hospital, Kolkata, West Bengal, India \\ ${ }^{2}$ Associate Professor, Department of Obstetrics and Gynecology, Assistant Team Leader of PPTCT Unit \\ Medical College and Hospital, Kolkata, West Bengal, India
}

Correspondence: Ranjana Tibrewal, Postgraduate Trainee, Department of Obstetrics and Gynecology, Flat 4D, MK Towers 301, Prince Anwar Shah Road, Kolkata-700045, West Bengal, India, Phone: 09831000379, e-mail: dr.ranjana@rediffmail.com

\section{ABSTRACT}

Objective: The purpose of this study was to investigate the various factors that influence pregnancy decisions in HIV positive women. Methods: This was a prospective observational study conducted in the Department of Obstetrics and Gynecology, Medical College and Hospital, Kolkata. Around 65 pregnant women testing positive for HIV and receiving care at our antenatal clinic or opting for MTP were included. An interview was taken regarding factors influencing reproductive decision making.

Results: Around $13.9 \%$ of the patients underwent MTP and $86.1 \%$ continued their pregnancy. When asked about the reason of opting for MTP, a varied response was noted out of which the fear for vertical transmission and concern of stigma took the major share.

Conclusion: The counseling approach is to be proposed that advocates encouraging HIV-infected women to make reasoned and considered decisions concerning childbearing. Such an approach would require providers to discuss with women not only the medical facts relevant to vertical transmission but also many of the psychosocial issues relevant to the woman's interest in bearing a child. Moreover, the encounter would be contextualized to include discussion of issues unique to the woman's situation and other family considerations.

Keywords: HIV status, Reproductive decision making, Abortion.

\section{INTRODUCTION}

HIV/AIDS is a life-threatening syndrome which has established itself as the modern pandemic. It is not merely a medical diagnosis but a diagnosis that has far reaching implications—physical, psychological and social. It was first reported in June 1981, by the Centers for Disease Control and Prevention (CDC), USA and ever since it has spread its deadly tentacles all over the globe.

The estimated number of people living with this infection, worldwide, in 2007 was 33.0 million. Out of this, there were 30.8 million adults and 2.0 million children $(<15$ years $){ }^{1}$ Women constituted almost $50 \%$ of the total infected adult population worldwide. It is important to note that every day, 6800 persons become infected with HIV and 5700 died from AIDS. Thus, HIV/AIDS remains the most serious amongst the infectious challenges to public health.

Latest estimates show that India has an approximate 2.31 million people living with HIV/AIDS - the national adult HIV prevalence being $0.34 \%$. Of this $39 \%$ are estimated to be females.

In the Indian society where fertility is often equated with feminity, and the women are under compulsion to bear healthy children in order to maintain their dignity and social status. But the most significant route of transmission of infection to children is vertical transmission. This study aims to analyze the role of various factors which influence the reproductive decisions made by the HIV-positive women in India.

\section{METHODS}

This was a prospective observational study conducted in the Department of Obstetrics and Gynecology, Medical College and Hospital, Kolkata. Around 65 pregnant women with the following inclusion criteria were recruited. Inclusion criteria: Pregnant women testing positive for HIV and receiving care at our antenatal clinic or opting for MTP.

All patients attending our antenatal clinic for the first time are subjected to universal screening for HIV infection. The group pretest counseling session is conducted where they are provided information about the infection of HIV and its progress to AIDS, magnitude of the problem, source of infection, methods of transmission and its prevention, MTCT (Mother to Child Transmission) and its prevention, the testing procedure with its benefits and risks, maintenance of confidentiality, and implications of positive or negative test results.

Blood is then collected on an 'opt-out' approach as recommended by NACO (National AIDS Control Organization), WHO, ACOG (American College of Obstetrician and Gynecologists), and tested by using rapid test kits as per strategy III of NACO.

The report is then given maintaining strict confidentiality and irrespective of the serological status, post-test counseling is done on one to one basis. During post-test counseling, those testing negative are reinformed about the behavioral changes for risk reduction, and the importance of protected intercourse 
to prevent new infection is emphasized upon. Those testing positive are given emotional support and their queries are answered. Various issues regarding prevention of vertical transmission, viz. mode of delivery, antiretroviral (ARV) prophylaxis, feeding options, partner testing, protected intercourse to prevent super infection with newer strains of the virus, etc. are discussed.

The women found HIV positive were recruited for the study. An interview was taken regarding factors influencing reproductive decision making.

The patients who so desired, were given the option of MTP whenever feasible, and services for the same were provided. Those who desired to continue pregnancy were provided routine antenatal care in our antenatal clinic.

\section{RESULTS AND ANALYSIS}

Table 1 shows $13.9 \%$ of the patients underwent MTP and 86.1\% continued their pregnancy. No patient presented with spontaneous abortion in this study.

Around 14 women (i.e. $21.5 \%$ ) of the study population knew their HIV positive status before the present pregnancy and among them eight (i.e. 57.14\%) opted for continuing pregnancy while six (i.e. 42.87\%) opted for MTP. Of the 51 (i.e.78.5\%) patients who were detected positive for the first time during the present pregnancy, 48 (i.e. 94.11\%) opted for pregnancy continuation. Only three out of 51 patients (5.88\%) opted for voluntary MTP in this group (Table 2).

\begin{tabular}{|l|rc|}
\hline Table 1 & Course of pregnancy $(\mathrm{n}=65)$ & \\
\hline Course & No. & Percentage \\
\hline MTP & 9 & 13.9 \\
Continuation & 56 & 86.1 \\
\hline Total & 65 & 100.0
\end{tabular}

Table 3 depicts the reproductive decision making in women who knew their seropositive status prior to pregnancy. Out of six primigravida women who knew their positive status before conception, five (83.33\%) chose to continue their pregnancy and only one underwent MTP, whereas out of the eight multigravida only three (37.5\%) continued their pregnancy whereas the majority, i.e five opted for MTP.

Table 4 shows the total numbers of women in our study were 65, out of which 14 were known positive and 51 were detected positive for the first time in this pregnancy. Out of 51 women, only 23 came to our antenatal clinic before 20 weeks of gestation, whereas the rest (i.e. 28) came for the first visit after 20 weeks of gestation, when the question of performing MTP does not arise. So, this table shows the results obtained in 23 women only. Amongst the women who came to know of their status first time during this pregnancy, majority wished to continue the pregnancy irrespective of their parity.

Table 5 analyzes the causes cited by the women for undergoing MTP. Out of 65 women in the study, nine underwent MTP. When asked about the reason of opting for MTP, a varied response was noted out of which the fear for vertical transmission and concern of stigma took the major share.

\section{DISCUSSION}

The desire for motherhood has been present since eternity. Irrespective of the HIV status, every woman nurtures the wish to become a mother in their marital life. Having a biological child of their own is also a factor tied up intimately with the position of the couple in the society as infertility itself is a stigma in our society. In a HIV positive woman, the major conflict is in between the joys of parenthood and the risk of transmission of the deadly disease to their newborn. This fear associated with the lack of support from the family often interferes and modifies the reproductive decision making in these women.

Table 2

Course of pregnancy among known positive patients and those detected positive for the first time during present pregnancy $(n=65)$

\begin{tabular}{|c|c|c|c|c|c|c|}
\hline \multirow[t]{2}{*}{ Course/status } & \multicolumn{2}{|c|}{ MTP } & \multicolumn{2}{|c|}{ Continuation of pregnancy } & \multicolumn{2}{|c|}{ Total } \\
\hline & No. & Percentage & No. & Percentage & No. & Percentage \\
\hline Known positive & 6 & 42.87 & 8 & 57.14 & 14 & 21.5 \\
\hline detected positive & 3 & 5.88 & 48 & 94.11 & 51 & 78.5 \\
\hline Total & 9 & 13.8 & 56 & 86.2 & 65 & 100 \\
\hline
\end{tabular}

\section{Table 3}

\begin{tabular}{|lll}
\hline & \multicolumn{2}{c}{ Parity } \\
\cline { 2 - 3 } & No. & Percentage \\
\hline $\mathrm{P}_{0}$ & 1 & 16.67 \\
$\mathrm{P}_{1-2}$ & 4 & 57.14 \\
$\mathrm{P}_{3-4}$ & 1 & 100 \\
\hline Total & 6 & 42.86 \\
\hline
\end{tabular}

Course of pregnancy opted for according to parity in known positive

\begin{tabular}{cllll}
\cline { 5 - 5 } Continuation of pregnancy & & \multicolumn{2}{c}{ Total } \\
\cline { 1 - 2 } \cline { 5 - 5 } No. & Percentage & & No. & Percentage \\
\hline 5 & 83.33 & 6 & 100 \\
3 & 42.86 & 7 & 100 \\
0 & - & 1 & 100 \\
\hline 8 & 57.14 & 14 & 100
\end{tabular}


Table 4 Course of pregnancy opted for according to parity in those detected positive during the present pregnancy

\begin{tabular}{|c|c|c|c|c|c|c|}
\hline \multirow[t]{2}{*}{ Parity } & \multicolumn{2}{|c|}{ MTP } & \multicolumn{2}{|c|}{ Continuation of pregnancy } & \multicolumn{2}{|c|}{ Total } \\
\hline & No. & Percentage & No. & Percentage & No. & Percentage \\
\hline$P_{0}$ & 1 & 8.33 & 11 & 91.67 & 12 & 100 \\
\hline$P_{1-2}$ & 1 & 10 & 9 & 90 & 10 & 100 \\
\hline$P_{3-4}$ & 1 & 100 & 0 & - & 1 & 100 \\
\hline Total & 3 & 13.04 & 20 & 86.96 & 23 & 100 \\
\hline
\end{tabular}

Table 5

Psychosocial factors influencing reproductive decision making (i.e. culminating in MTP in nine cases)

\begin{tabular}{|lcc|}
\hline Psychosocial factors & No. & Percentage \\
\hline Fear of stigma & 4 & 23.53 \\
Lack of family support & 3 & 17.65 \\
Fear of vertical transmission & 5 & 29.41 \\
Positive status of previous child & 2 & 11.76 \\
Low socioeconomic status & 3 & 17.65 \\
\hline Total & 17 & 100.00 \\
\hline
\end{tabular}

Around $21.5 \%$ of the study population knew their HIV positive status before the present pregnancy and a huge majority (78.5\%) was detected positive for the first time during the present pregnancy. It was seen that amongst those who knew the status before conceiving, the trend of keeping and terminating the pregnancy was very close $(57.14 \%$ wanted to continue and 42.87\% opted for MTP). This was in sharp contrast with the desire of those who were detected positive during pregnancy (94.11\% continued and only 5.88\% chose to terminate).

Amongst the known positive women, the majority of the primigravidas wanted to have their child born whereas the multigravidas mostly opted for MTP. But amongst those who came to know of their status in the current pregnancy, majority of both the primigravida and the multigravida wanted to continue the pregnancy, thus reflecting that their primary plan and mental involvement was with the desire of achieving motherhoodHIV being an incidental detection in the course of investigation in pregnancy. Chen $\mathrm{JL}$ et $\mathrm{al}^{3}$ found that overall 28 to $29 \%$ of HIV-infected men and women receiving medical care in the United States desire children in the future. Among those desiring children, $69 \%$ of women and $59 \%$ of men actually expect to have one or more children in the future. The proportion of HIVinfected women desiring a child in the future is somewhat lower than the overall proportion of US women who desire a child. HIV-positive individuals who desire children are younger, have fewer children and report higher ratings of their physical functioning or overall health than their counterparts who do not desire children, yet desire for future childbearing is not related to measures of HIV progression. HIV-positive individuals who expect children are generally younger, and less likely to be married than those who do not.

Oladapo $^{3}$ et al noted in their study that $63.3 \%$ of the 147 studied participants expressed the desire for childbearing, even though $50.4 \%$ of them already had $\geq 2$ children. Respectively, $71.5 \%$ and $93.8 \%$ of men and women who desired children intended to have $\geq 2$ in the near future. Only $4.3 \%$ of those who desired children did not intend to have any. All 30 individuals who had no children intended to bear children in the future, and they constituted 32.3\% of those who expressed the desire for childbearing. Multivariate logistic regression analyzes of associated factors indicated that decreasing age, shorter time since diagnosis of HIV infection and nondisclosure of serostatus to current partner significantly increase the odds of desire for childbearing, while having no children and a poor most-recent CD4 count significantly increase the odds of intention to have $\geq 3$ children instead of 1 to 2 .

Out of 65 women in our study nine underwent MTP. We observed that the main reason of choosing MTP was fear of vertical transmission followed by that of stigma. The threat of shortened life span due to this deadly disease often looms over the minds of the couple and this along with the lack of family support as a result of discrimination often drive them towards curbing their desire for parenthood. In a study in Chennai, by Kannaiappan S, ${ }^{4}$ what emerged was that the main factors distinguishing women who wanted to have a child and those who did not were their levels of anxiety about the future and available family support. Women who indicated that they did not have family support and were stigmatized by the family were reluctant to opt for a pregnancy as they were not sure of the future, including child care in event of parental death. In contrast, those women who decided to have a child did so based on family support, especially when family members offered to take care of the child in the future in the event of parental death. Kirshenbaum $^{5}$ et al observed that regardless of women's pregnancy experiences or intentions, reproductive decisionmaking themes included the perceived risk of vertical transmission, which was often overestimated; beliefs about vertical transmission risk reduction strategies, desire for motherhood, stigma, religious values, attitudes of partners and health care providers, and the impact of the mother's health and longevity on the child. Most women who did not want children after their diagnosis cited vertical transmission risk as the reason.

Nearly $80 \%$ of women currently infected with HIV are of childbearing age. As women of childbearing age continue to be at risk of contracting HIV, there will be an increased need for choices about whether or not to have biological children. Women with a procreative inclination are more likely to choose to become pregnant which outweigh social support and personal health concerns. A counseling approach is to be proposed that advocates encouraging HIV-infected women to make reasoned 
and considered decisions concerning childbearing. Such an approach would require providers to discuss with women not only the medical facts relevant to vertical transmission but also many of the psychosocial issues relevant to the woman's interest in bearing a child. Moreover, the encounter would be contextualized to include discussion of issues unique to the woman's situation and other family considerations. Most appropriate at this time appears to be a moral education model of nondirective counseling aimed at providing support to a woman's choice after she has pondered all the ethical dilemmas posed by reproduction. HIV infection is only one of many conditions of chronic disease that can be passed from a woman to her fetus, and should not be singled out as a target for coercive policies. Rather, government and society have an obligation to empower women to protect themselves against HIV infection in the first place, and to offer them options for self-esteem and achievement independent of reproduction.

\section{REFERENCES}

1. Available from http:// www.avert.org/aidsindia.htm, published by UNAIDS/WHO in July 2008 and refer to the end of 2007.

2. Chen JL, Philips KA, Kanouse DE, Collins RL, Miu A. Fertility desires and intentions of HIV-positive men and women. Fam Plann Perspect Jul-Aug 2001;33(4):144-52, 165.

3. Oladapo OT, Daniel OJ, Odusoga OL, Ayoola-Sotubo O. Fertility desires and intentions of HIV-positive patients at a suburban specialist center. J Natl Med Assoc Dec 2005;97(12):1672-81.

4. Kanniappan S, Jeyapaul MJ, Kalyanwala S. Desire for motherhood: Exploring HIV-positive women's desires, intentions and decision-making in attaining motherhood. AIDS Care Jul 2008; 20(6):625-30.

5. Kirshenbaum SB, Hirky AE, Correale J, Goldstein RB, Johnson MO, Rotheram-Borus MJ, Ehrhardt AA. "Throwing the dice": Pregnancy decision-making among HIV-positive women in four US cities. Perspect Sex Reprod Health. May-Jun 2004;36(3): 106-13. 